Check for updates

Cite this: RSC Adv., 2020, 10, 34534

Received 25th May 2020

Accepted 5th September 2020

DOI: $10.1039 / \mathrm{dOra04621 \textrm {c }}$

rsc.li/rsc-advances

\title{
One pot synthesis of trifluoromethyl aryl sulfoxides by trifluoromethylthiolation of arenes and subsequent oxidation with hydrogen peroxide $\uparrow$
}

\begin{abstract}
Monika Horvat, Gregor Kodrič, Marjan Jereb (ID) and Jernej Iskra (DD*
Hydrogen peroxide was used for oxidation of various aryl trifluoromethyl sulfides. Trifluoroacetic acid was used as an activating solvent that enables non-catalyzed oxidation and increases selectivity for sulfoxide formation. As shown by oxidation of thianthrene TFA enhances electrophilic character of the oxidant and further oxidation of sulfoxide group is blocked. We have joined trifluoromethylthiolation of arenes using a modified Billard reagent $\left(p-\mathrm{ClPhNHSCF}_{3}\right.$ ) with oxidation of aryl trifluoromethyl sulfides using 1.2 equiv. of $30 \%$ aqueous hydrogen peroxide and this one-pot process has superior yields than would have been obtained in a two step process.
\end{abstract}

\section{Introduction}

Organofluorine compounds have great potential in the development of new materials, bioactive compounds, agrochemicals, pharmaceutical compounds and in many other areas. ${ }^{1,2}$ They are interesting because of their chemical, physical and physiological properties. ${ }^{3}$ The trifluoromethylsulfanyl group $\left(\mathrm{SCF}_{3}\right)$ has a high lipophilicity parameter (1.44) and a strong electronwithdrawing effect., ${ }^{4,5}$ It has a slightly weaker electronwithdrawing character (Hammett constant: $\sigma_{m}=0.40, \sigma_{p}=$ $0.50)$ than the trifluoromethyl group $\left(\mathrm{CF}_{3}\right)$ (Hammett constant: $\left.\sigma_{m}=0.43, \sigma_{p}=0.54\right)$. Functional groups $\mathrm{SOCF}_{3}$ and $\mathrm{SO}_{2} \mathrm{CF}_{3}$ have even stronger electron-withdrawing character $\left(\mathrm{SOCF}_{3}: \sigma_{m}\right.$ $\left.=0.63, \sigma_{p}=0.69 ; \mathrm{SO}_{2} \mathrm{CF}_{3}: \sigma_{m}=0.79, \sigma_{p}=0.93\right)$ than $\mathrm{CF}_{3}{ }^{6}$ Organic compounds with $\mathrm{SOCF}_{3}$ and $\mathrm{SO}_{2} \mathrm{CF}_{3}$ groups are not as common as $\mathrm{SCF}_{3}$ compounds due to their problematic synthesis. However, they show pharmacological and biological activities (antibacterial, antimalarial, anti-pneumonia and nervous anorexia treatment) and they are already on the market e.g. fipronil, ponazuril., ${ }^{7,8}$

Trifluoromethyl aryl sulfoxides can be prepared directly from different aromatic molecules by sulfinylation of aromatics by triflinate salts in acidic medium, ${ }^{9}$ by $\mathrm{CF}_{3} \mathrm{SO}_{2} \mathrm{Cl} / \mathrm{PCy}_{3}$ reagent ${ }^{10}$ and by thia-Fries rearrangement process in the presence of $\mathrm{AlCl}_{3}$ (Scheme 1). ${ }^{11}$ In 1999 Langlois reported on the synthetic method for trifluoromethanesulfinates and trifluoromethanesulfinamides using the $\mathrm{CF}_{3} \mathrm{SO}_{2} \mathrm{Na} / \mathrm{POCl}_{3}$ system. $^{12}$ They can also be prepared with 1(trifluoromethylsulfinyl)pyrrolidine-2,5-dione in good yields. ${ }^{13}$

Faculty of Chemistry and Chemical Technology, University of Ljubljana, Večna pot 113, 1000 Ljubljana, Slovenia.E-mail: jernej.iskra@fkkt.uni-lj.si

$\dagger$ Electronic supplementary information (ESI) available. See DOI: $10.1039 /$ d0ra04621c
Allylic trifluoromethanesulfenates can be prepared from allylic alcohols using $\left[\mathrm{N}-\mathrm{SCF}_{3}\right]^{+}$reagent via a $[2,3]$-sigmatropic rearrangement. ${ }^{14}$ ortho-Trifluoromethanesulfinyl anilines can be synthesized by intermolecular $\mathrm{C}-\mathrm{N}$ addition of amides and $\mathrm{S}-\mathrm{N}$ addition of sulfinamides to arynes (Scheme 1). ${ }^{15}$ Opposite strategy is introduction of $\mathrm{CF}_{3}$ group into sulfinic esters or sulfinyl halides using $\mathrm{TMSCF}_{3}$ reagent and fluoride activator. $^{16,17}$

Researchers have discovered new processes for the selective oxidation of sulfides to corresponding sulfoxides, which are easy to handle, green and cost-effective. Trifluoromethyl sulfides are less reactive for oxidation and various oxidizing

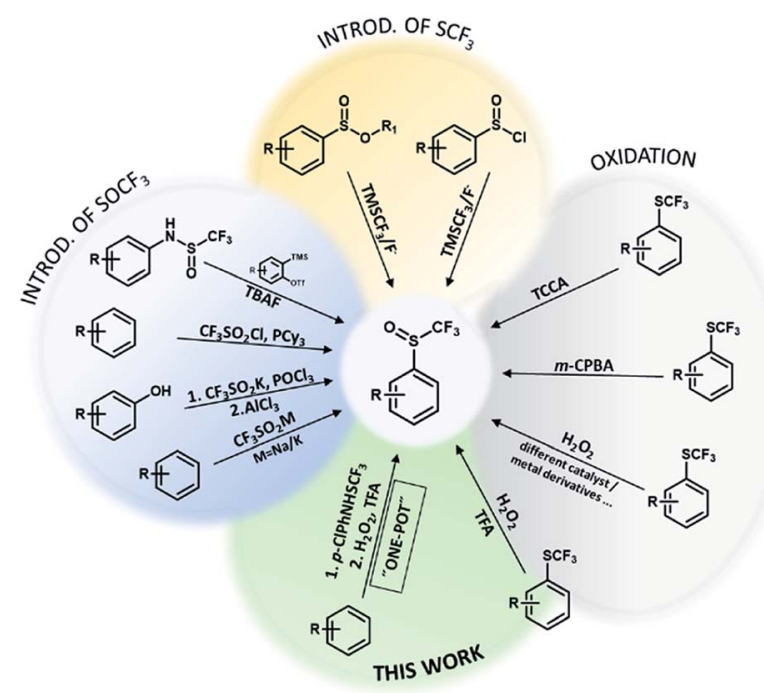

Scheme 1 Different ways for preparation of aryl trifluoromethyl sulfoxides. 
agents such as $m$-CPBA, $\mathrm{CF}_{3} \mathrm{CO}_{3} \mathrm{H}, \mathrm{NaIO}_{4}$, TCCA, cyclic diacyl peroxide, Oxone, $\mathrm{MoO}_{2} \mathrm{Cl}_{2}\left(\mathrm{OPPH}_{3}\right)_{2} / \mathrm{Cu}\left(\mathrm{NO}_{3}\right)_{2}$ have been used and only two examples with $\mathrm{H}_{2} \mathrm{O}_{2}\left(\mathrm{~F}_{20}\right.$ TPPFe and TFA) were reported (Scheme 1). ${ }^{\mathbf{3 , 1 8 - 2 2}}$ As trifluoromethyl sulfides are less reactive, selectivity of oxidation is problematic and overoxidation to sulfones occurs readily. The problem with most oxidants is the formation of toxic waste and environmentally harmful by-products (metal salts, reagent residues). ${ }^{23}$ Most of them are expensive, oxidation is very temperature sensitive and overoxidation can lead to the formation of unfavorable byproduct (trifluoromethyl sulfone). ${ }^{18}$ In recent years, research has focused on the development of an effective, simple and selective route for the synthesis of trifluoromethyl sulfoxides under mild reaction conditions using safe and clean oxidation processes. $\mathrm{H}_{2} \mathrm{O}_{2}$ is an attractive oxidant, inexpensive, soluble in water and many organic solvents, and environmentally friendly, since water is the only theoretical by-product. ${ }^{23,24}$ Oxidation with $\mathrm{H}_{2} \mathrm{O}_{2}$ is useful for the synthesis of pharmaceuticals and agrochemicals, which requires high chemical purity. ${ }^{\mathbf{2 4 5}}$ The problem with hydrogen peroxide is that it reacts slowly with organic compounds and must be activated. There are many reports of the hydrogen peroxide based oxidation of sulfides to corresponding sulfoxides under appropriate activation conditions (nucleophilic, electrophilic and radical activation) using transition metal or organic catalyst, ${ }^{\mathbf{2 3 2 6 - 2 8}}$ while $\mathrm{H}_{2} \mathrm{O}_{2}$ was also activated with fluorinated alcohols ${ }^{29}$ (Scheme 1).

Studies on oxidation of aromatic trifluoromethyl sulfides with $\mathrm{H}_{2} \mathrm{O}_{2}$ are limited. In 2019 Yagupolskii reported on the oxidation protocol for the oxidation of $\mathrm{CF}_{3} \mathrm{~S}$ to the $\mathrm{CF}_{3} \mathrm{~S}(\mathrm{O})$ group using $15 \%$ hydrogen peroxide in trifluoroacetic acid. During the oxidation no further unwanted oxidation to trifluoromethyl sulfone occurred. This method has some disadvantages, such as the incomplete conversion of the trifluoromethyl sulfides to sulfoxides. In a few cases the conversion was complete, in others $87-98 \% .^{30}$ The method for direct synthesis of trifluoromethyl sulfoxides from aromatic molecules by introduction of $\mathrm{SCF}_{3}$ group followed by oxidation has not yet been investigated. Due to the limited set of available aryl trifluoromethyl sulfides, the one-pot procedure is very desirable. The trifluoromethylsulfanyl group $\left(\mathrm{SCF}_{3}\right)$ can be introduced into the aromatic molecules with various electrophilic reagents. ${ }^{\mathbf{6}, 31,32}$ One of the most commonly and widely used reagent is the Billard reagent $\mathrm{PhNHSCF}_{3},{ }^{33,34}$ while reagent $p$ $\mathrm{ClPhNHSCF}_{3}$ is suited for the use on wider range of arenes. ${ }^{35} \mathrm{We}$ present in this report effective, simple and highly selective method for the one-pot synthesis of various aryl trifluoromethyl sulfoxides from different activated and deactivated aromatic molecules by trifluoromethylthiolation with the stable and easy

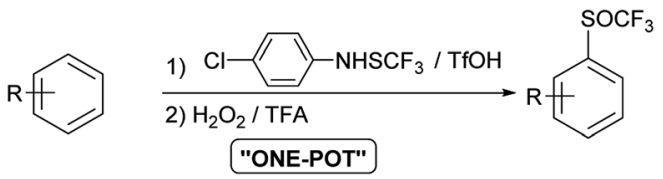

Scheme 2 One-pot synthesis of trifluoromethyl sulfoxides from different aromatic molecules. to use reagent $p$-ClPhNHSCF${ }_{3},{ }^{35}$ followed by oxidation with $\mathrm{H}_{2} \mathrm{O}_{2}$ in TFA (Scheme 2).

\section{Results and discussion}

Phenyl trifluoromethyl sulfide 1a was chosen as model substrate for an initial study on the effect of reaction conditions on the selective oxidation of the trifluoromethylsulfanyl group $\left(\mathrm{SCF}_{3}\right)$ with hydrogen peroxide as an oxidant. The sulfur atom is deactivated for oxidation because of the electron-withdrawing $\mathrm{CF}_{3}$ group and must be activated. We examined the effect of different solvents, the concentration of hydrogen peroxide, transition metals, Brønsted and Lewis acids on the oxidation of the sulfur atom.

First, we investigated the oxidation of trifluoromethyl sulfide 1a to the corresponding trifluoromethyl sulfoxides 2 a or sulfones 3a with $30 \% \mathrm{H}_{2} \mathrm{O}_{2}$ in different solvents such as nonpolar solvent $\left(\mathrm{PhCH}_{3}\right)$, polar aprotic solvents (DCM, EtOAc, $\mathrm{MeCN})$, polar protic solvents (EtOH, i-PrOH) and fluorinated alcohols (TFE, HFIP) (Table 1). A solution of trifluoromethyl sulfide $1 \mathrm{a}$ in selected solvent and 2 equiv. of $30 \%$ aqueous hydrogen peroxide was stirred at room temperature for $24 \mathrm{~h}$. Afterwards the conversion was determined by ${ }^{1} \mathrm{H}$ NMR spectroscopy of the crude reaction mixture. The experimental results in Table 1 show that a small amount of product 2a was formed only in the HFIP. In other solvents oxidation did not occur.

Fluorinated alcohols strongly activate hydrogen peroxide by their high ionizing power, strong hydrogen bond donor ability and weak hydrogen bond acceptor strength. HFIP has a stronger effect than TFE. It is known that the activation of 30\% hydrogen peroxide by HFIP is strong enough to selectively oxidize sulfides to sulfoxides. ${ }^{36}$ Furthermore, HFIP deactivates sulfoxide for further oxidation to sulfone by its interaction with sulfoxide group. In the case of sulfide 1a, the deactivating effect of the trifluoromethyl group outweights activation by HFIP. We have

Table 1 The effect of solvent on oxidation of 1 a with $\mathrm{H}_{2} \mathrm{O}_{2}{ }^{a}$

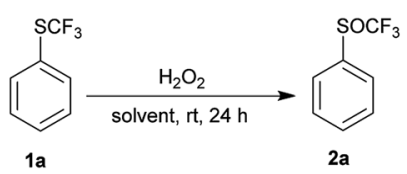

\begin{tabular}{|c|c|c|c|}
\hline Entry & \multicolumn{2}{|l|}{ Solvent } & Conv. $^{b}[\%]$ \\
\hline 1 & Non-polar & $\mathrm{PhCH}_{3}$ & 0 \\
\hline 2 & Polar aprotic & DCM, EtOAc, MeCN & 0 \\
\hline 3 & Polar protic & EtOH, i-PrOH & 0 \\
\hline 4 & Fluorinated alcohols ${ }^{c}$ & TFE & 0 \\
\hline 5 & & HFIP $(30 \%)$ & 12 \\
\hline 6 & & HFIP (50\%) & 15 \\
\hline 7 & & HFIP (100\%) & 16 \\
\hline 8 & & $\operatorname{HFIP}^{d}(30 \%)$ & 50 \\
\hline
\end{tabular}


Table 2 Oxidation of $1 a$ with $\mathrm{H}_{2} \mathrm{O}_{2}$ in presence of different activators ${ }^{a}$

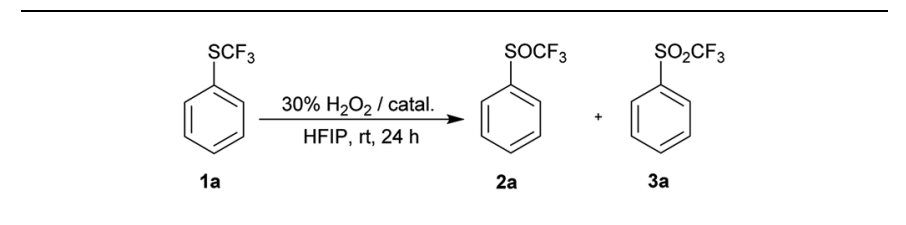

\begin{tabular}{|c|c|c|c|c|}
\hline \multirow[b]{2}{*}{ Entry } & \multirow[b]{2}{*}{ Activator } & \multirow[b]{2}{*}{ Conv. $^{b}[\%]$} & \multicolumn{2}{|c|}{$\begin{array}{l}\text { Product } \\
\text { selectivity } \\
{[\%]}\end{array}$} \\
\hline & & & $2 \mathbf{a}$ & $3 \mathbf{a}$ \\
\hline 1 & $\mathrm{HCl}$ & 100 & 99 & 1 \\
\hline 2 & $\mathrm{H}_{2} \mathrm{SO}_{4}$ & 100 & 99 & 1 \\
\hline 3 & $\mathrm{TfOH}$ & 100 & 99 & 1 \\
\hline 4 & TFA & 11 & 100 & 0 \\
\hline 5 & $\mathrm{AcOH}$ & 0 & 0 & 0 \\
\hline 6 & $\mathrm{BF}_{3} \cdot \mathrm{Et}_{2} \mathrm{O}$ & 99 & 98 & 2 \\
\hline 7 & $\mathrm{H}_{2} \mathrm{WO}_{4}$ & 100 & 95 & 5 \\
\hline 8 & $\mathrm{CH}_{3} \mathrm{ReO}^{c}$, pyridine ${ }^{c}$ & 97 & 100 & 0 \\
\hline 9 & $\mathrm{FeCl}_{3}$, pyridine & 10 & 100 & 0 \\
\hline
\end{tabular}

${ }^{a}$ Reaction conditions: phenyl trifluoromethyl sulfide $1 \mathrm{a}(0.5 \mathrm{mmol})$, $\mathrm{H}_{2} \mathrm{O}_{2}(0.6 \mathrm{mmol}, 30 \%)$, catalyst $(10 \mathrm{~mol} \%)$, HFIP $(2 \mathrm{~mL}), \mathrm{rt}, 24 \mathrm{~h}$. ${ }^{b}$ Conversion to product was determined by ${ }^{1} \mathrm{H}$ NMR. ${ }^{c} 1 \mathrm{~mol} \%$ of activator.

tried to increase the reaction with more concentrated hydrogen peroxide $(50 \%$ and $100 \%)$. Surprisingly, the concentration of $\mathrm{H}_{2} \mathrm{O}_{2}$ had only a minor influence on the conversion (Table 1, entries 5-7). Only at the reflux temperature $50 \%$ of 2 a were formed.

Since the activation by HFIP itself was not strong enough to achieve complete oxidation of 1a, we decided to investigate the effect of stronger activators, such as metal catalysts, Brønsted and Lewis acids. We used only 1.2 equiv. of $\mathrm{H}_{2} \mathrm{O}_{2}$ and $10 \mathrm{~mol} \%$ catalyst in these reactions to reduce over-oxidation. Strong Brønsted acids catalyzed the oxidation of 1a and complete conversion was observed in 24 hours at room temperature, but trace amounts of sulfone 3a were also formed (Table 2, entries 1-3). TFA - a weaker acid, was not so effective, while no reaction occurred in acetic acid (entries 4 and 5). Activation with Lewis acid $\mathrm{BF}_{3} \cdot \mathrm{OEt}_{2}$ led to a similar result as with strong acids. Selected metal-catalyzed oxidation depended on the metal $\mathrm{H}_{2} \mathrm{WO}_{4}$ was the least selective catalyst, MTO did not give complete conversion, while $\mathrm{FeCl}_{3}$ gave similar results to TFA (Table 2, entries 7-9).

Since TFA had some catalytic activity, we decided to use it as a solvent for oxidation of $1 \mathrm{a}$ to $2 \mathrm{a}$. To a solution of trifluoromethyl sulfide 1a in TFA 1.2 equiv. of $30 \%$ aqueous hydrogen peroxide was added. The reaction mixture was stirred at room temperature and $\mathbf{1 a}$ was completely oxidized within three hours with formation of trifluoromethyl sulfoxide $\mathbf{2 a}$ and sulfone 3a in ratio $97: 3$ (Table 3, entry 1). Analogous oxidation of $1 \mathrm{a}$ in $\mathrm{AcOH}$ was slower and conversion after 48 hours reaction was $80 \%$. Promising results in TFA lead to further optimization. The use of an equimolar amount of $\mathrm{H}_{2} \mathrm{O}_{2}$ led to a selective formation of sulfoxide $2 \mathrm{a}$ with $96 \%$ conversion in $3 \mathrm{~h}$ at room
Table 3 The effect of the reaction conditions on oxidation of 1a with $\mathrm{H}_{2} \mathrm{O}_{2}$ in TFA ${ }^{a}$

\begin{tabular}{|c|c|c|c|c|c|}
\hline & 1a & $\frac{30 \% \mathrm{H}_{2} \mathrm{O}_{2}}{\text { TFA, } 3 \mathrm{~h}}$ & $\mathrm{SOCF}_{3}$ & $\mathrm{SO}_{2} \mathrm{CF}$ & \\
\hline \multirow[b]{2}{*}{ Entry } & \multirow[b]{2}{*}{ Temp. } & \multirow[b]{2}{*}{ Equiv. $\mathrm{H}_{2} \mathrm{O}_{2}$} & \multirow[b]{2}{*}{ Conv. $^{b}[\%]$} & \multicolumn{2}{|c|}{$\begin{array}{l}\text { Product } \\
\text { selectivity [\%] }\end{array}$} \\
\hline & & & & 2 & 3 \\
\hline 1 & Rt & 1.2 & 100 & 97 & 3 \\
\hline 2 & Rt & 1.0 & 96 & 100 & 0 \\
\hline 3 & Rt & $1.0^{c}$ & 94 & 100 & 0 \\
\hline 4 & $0^{\circ} \mathrm{C}$ & 1.0 & 65 & 100 & 0 \\
\hline 5 & $0^{\circ} \mathrm{C}$ & 1.2 & 67 & 100 & 0 \\
\hline 6 & $0{ }^{\circ} \mathrm{C}$ & 1.5 & 84 & 100 & 0 \\
\hline 7 & $0^{\circ} \mathrm{C}$ & 2.0 & 100 & 99 & 1 \\
\hline 8 & $\mathbf{0}^{\circ} \mathrm{C}$ & $1.2^{c}$ & 100 & 100 & $\mathbf{0}$ \\
\hline 9 & $60{ }^{\circ} \mathrm{C}$ & 2.4 & 100 & 4 & $96(95 \%)^{d}$ \\
\hline
\end{tabular}

${ }^{a}$ Reaction conditions: phenyl trifluoromethyl sulfide $1(0.5 \mathrm{mmol})$, $\mathrm{H}_{2} \mathrm{O}_{2}(0.5-1.2 \mathrm{mmol}, 30 \%)$, TFA $(2 \mathrm{~mL}), 3 \mathrm{~h} .{ }^{b}$ Conversion to product was determined by ${ }^{1} \mathrm{H}$ NMR. ${ }^{c}$ Reaction time: 6 h. ${ }^{d}$ Isolated yield.

temperature (Table 3, entry 2), however reaction did not proceed to completion even after prolonged reaction time (Table 3, entry 3 ). The reaction at $0{ }^{\circ} \mathrm{C}$ was slower and a higher conversion was achieved with a higher excess of $\mathrm{H}_{2} \mathrm{O}_{2}$ (Table 3, entries 4-7). The quantitative conversion was achieved with two equivalents of the oxidant, but a small amount of over-oxidized product 3a was present in the reaction mixture. The quantitative and selective conversion of 1a to $2 \mathrm{a}$ was achieved with 1.2 equiv. of $\mathrm{H}_{2} \mathrm{O}_{2}$ at $0{ }^{\circ} \mathrm{C}$ in 6 hours (Table 3, entry 8). Sulfone 3 a was difficult to form in TFA and harsher conditions were required -2.4 equiv. of hydrogen peroxide at $60^{\circ} \mathrm{C}$ led to formation of sulfone $3 \mathrm{a}$ with a yield of $96 \%$ (Table 3, entry 9).

We applied the knowledge gained in initial studies to oxidize various aromatic trifluoromethyl sulfides 1 . Due to limited commercial availability, a library of trifluoromethyl sulfides $\mathbf{1}$ was prepared from various activated and deactivated aromatic substrates using our method with $p$-ClPhNHSCF ${ }_{3}{ }^{35}$ The best conditions for the preparation of $2 \mathrm{a}$ (1.2 equiv. of $30 \% \mathrm{H}_{2} \mathrm{O}_{2}$, $0{ }^{\circ} \mathrm{C}, \mathrm{TFA}$ ) were applied. To a solution of trifluoromethyl sulfide 1 in TFA, 1.2 equiv. of $30 \% \mathrm{H}_{2} \mathrm{O}_{2}$ was added and the reaction mixture was stirred at $0{ }^{\circ} \mathrm{C}$ until the sulfide was consumed, as determined by GC-MS. In all cases a selective and quantitative transformation to trifluoromethyl sulfoxide 2 was observed and we prepared thirteen trifluoromethyl sulfoxides 2 (Scheme 3) with electron-donating and electron-withdrawing groups on the aromatic ring in $77-95 \%$ yield. The oxidation tolerated the presence of hydroxyl, acetyl and hydroxymethyl groups on the aryl ring. On the other hand, the formyl group is not tolerated and $p$-formylphenyl trifluoromethyl sulfide was converted into a complex mixture of products. The phenanthryl derivative $\mathbf{1 m}$ was also oxidized in $85 \%$ yield to the corresponding sulfoxide $2 \mathrm{~m}$. 


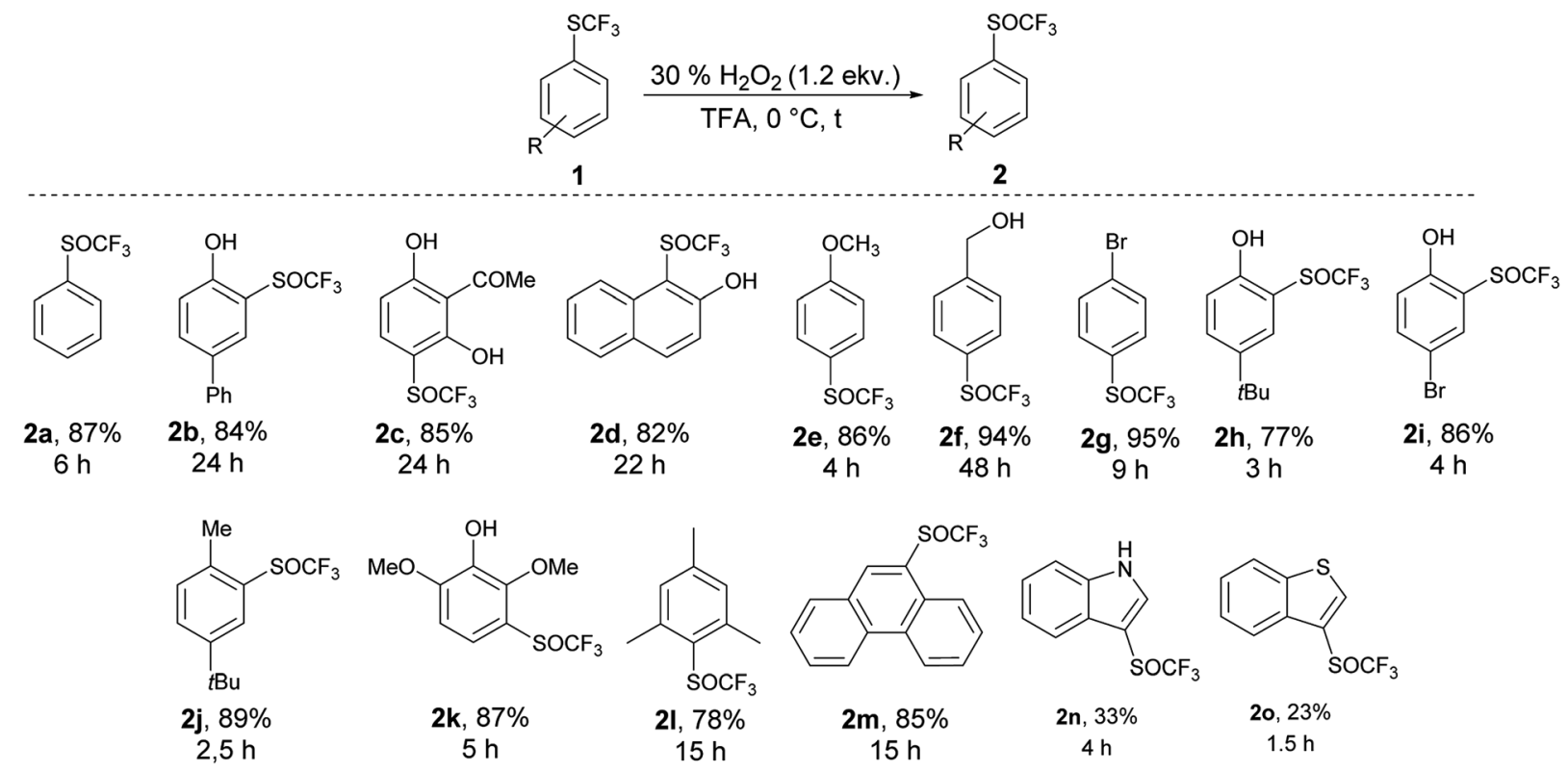

Scheme 3 Selective oxidation of aryl trifluoromethyl sulfides 1.

An introduction of the $\mathrm{SCF}_{3}$ group into heteroaromatic ring is difficult and pyridine, imidazole and benzothiazole failed to react under these reaction conditions. On the other hand, pyrrole was converted into a complex mixture of products. Furthermore, sulfur atom in $\mathrm{SCF}_{3}$ group is very deactivated for oxidation leading to problems with selectivity of oxidation of substrates with various functional groups. We made a further study on the series - benzofuran, benzothiophene and indole to see how heteroatoms affects the oxidation. Trifluoromethylthiolation of benzofurane did not occur under the classical reaction conditions and only starting compound was recovered. Indole and benzothiophene were selectively transformed to the corresponding trifluoromethylthiolated derivatives 1n and 1o, respectively. ${ }^{35}$ Indole was selectively and quantitatively trifluoromethylthiolated to give 3-((trifluoromethyl)thio)- $1 H$-indole 1 n, which was oxidized under the standard reaction conditions to the desired trifluoromethyl sulfoxide $\mathbf{2 n}$ and isolated in $33 \%$ yield (Scheme 3). A lower yield is attributed to the formation of a complex mixture of products.

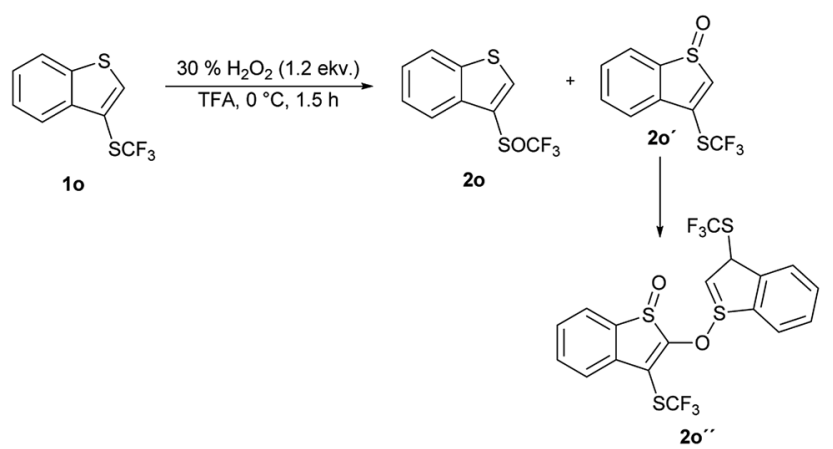

Scheme 4 Oxidation of 3-((trifluoromethyl)thio)benzo[b]thiophene 10.
3-((Trifluoromethyl)thio)benzo[ $b]$ thiophene 10 has been completely oxidated, but oxidation occurred on both sulfur atoms and a mixture of $\mathbf{2 0}$ and 3-((trifluoromethyl)thio)benzo $[b]$ thiophene 1-oxide $2 \mathrm{o}^{\prime}$ in the ratio $34: 66$ was formed. We isolated both products, however the side product $\mathbf{2 o}^{\prime}$ is not stable and starts to decompose during isolation procedure into the product $2 \mathbf{2}^{\prime \prime}$ (Scheme 4). This surprising reaction could be a result of a hetero Diels-Alder additions followed be a hydride shift. The product $\mathbf{2 \mathbf { o } ^ { \prime \prime }}$ also decomposes slowly into a complex mixture of products.

TFA as solvent is a very effective activator of $\mathrm{H}_{2} \mathrm{O}_{2}$. As in template catalysis in fluorinated alcohols, ${ }^{29}$ formation of hydrogen bonds between $\mathrm{ArSCF}_{3}$ 1, TFA and $\mathrm{H}_{2} \mathrm{O}_{2}$ could be the reason for the activation. Furthermore, the interaction between sulfoxide 2 and TFA could reduce the nucleophilicity of the sulfur atom and deactivate the $\mathrm{SOCF}_{3}$ group for further

Table 4 Selectivity of oxidation of $1 \mathrm{j}$ with different $\mathrm{H}_{2} \mathrm{O}_{2}$ and $m-\mathrm{CPBA}^{a}$
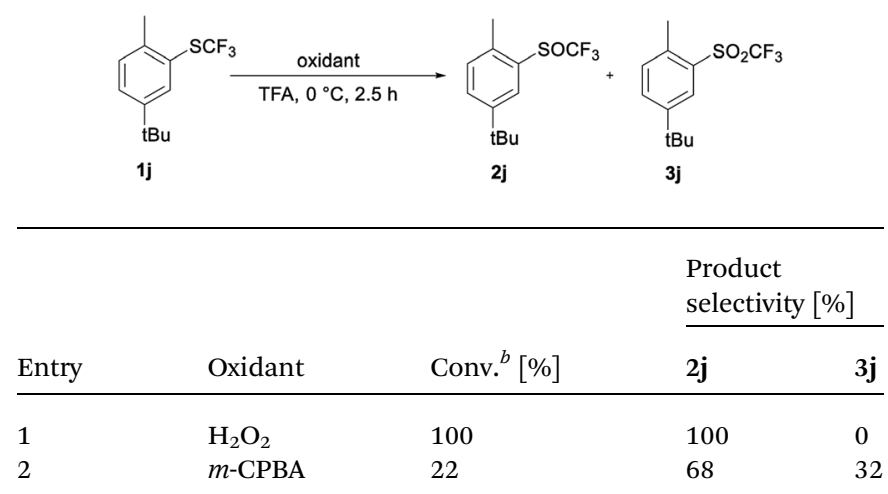

${ }^{a}$ Reaction conditions: $\mathbf{1 j}$ (0.5 mmol), oxidant $(1.0 \mathrm{mmol})$, TFA $(5 \mathrm{~mL})$, $2.5 \mathrm{~h}, 0{ }^{\circ} \mathrm{C} .{ }^{b}$ Conversion to product was determined by ${ }^{1} \mathrm{H}$ NMR. 


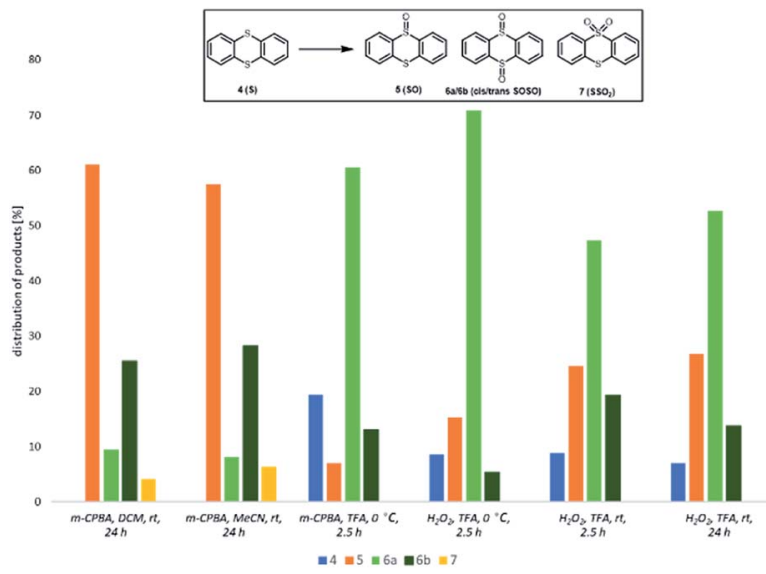

Fig. 1 Selectivity of oxidation of thianthrene 4 (reaction conditions: 4 $(0.5 \mathrm{mmol})$, oxidant $(1.0 \mathrm{mmol})$, solvent $(5 \mathrm{~mL})$, time. Product distribution was determined by ${ }^{1} \mathrm{H}$ NMR spectroscopy).

oxidation to the sulfones. ${ }^{29}$ To test the specific interaction of TFA and $\mathrm{H}_{2} \mathrm{O}_{2}$ in selective oxidation, we compared the results of the oxidation of sulfide $1 \mathbf{j}$ with $\mathrm{H}_{2} \mathrm{O}_{2}$ and with meta-chloroperoxybenzoic acid ( $m$-CPBA). ${ }^{37}$

Table 4 shows data for the oxidation of sulfide $1 \mathrm{j}$ to sulfoxide $2 \mathbf{j}$ or sulfone $3 \mathbf{j}$ with $m$-CPBA and with $30 \% \mathrm{H}_{2} \mathrm{O}_{2}$. $\mathbf{1 j}$ is oxidized selectively and quantitatively with 1.2 equiv. of $30 \% \mathrm{H}_{2} \mathrm{O}_{2}$ in TFA in 2.5 hours at $0{ }^{\circ} \mathrm{C}$. An analogous reaction with $m$-CPBA is less effective and less selective in TFA. Under the same reaction conditions the conversion is only $22 \%$, while a significant amount of sulfone $\mathbf{3} \mathbf{j}$ is already formed.

To further elucidate the role of trifluoroacetic acid in this reaction we have turned to thianthrene $\mathbf{4}$ as a model substrate. Adam and his coworkers have studied the oxidation of thianthrene 5-oxide (SO) as a mechanistic probe to determine the electronic character of various oxidising agents. Electrophilic oxidants oxidize $\mathrm{SO}$ at the sulfide $\mathrm{S}$-atom to give sulfoxide SOSO, while nucleophilic oxidants react preferentially at the sulfoxide S-atom to afford sulfone $\mathrm{SSO}_{2}{ }^{38,39}$

We compared selectivity of oxidation of thianthrene 4 with $\mathrm{m}$ CPBA and with $\mathrm{H}_{2} \mathrm{O}_{2}$ in three solvents - DCM, MeCN and TFA. As presented in Fig. 1, oxidation with 2 equiv. of $m$-CPBA in DCM and $\mathrm{MeCN}$ proceeded at room temperature with $100 \%$ conversion. The main product was sulfoxide SO 5 , while some sulfone $\mathrm{SSO}_{2} 7$ already formed. Reaction in TFA was performed at $0{ }^{\circ} \mathrm{C}$ and the main reaction channel was oxidation of both sulfur atoms with formation of SOSO 6 with the major stereoisomer being cis-SOSO 6a. The result is in accordance with the effect of TFA. ${ }^{40}$ No formation of $\mathrm{SSO}_{2} 7$ was observed. Oxidation of thianthrene $\mathrm{S} 4$ with $\mathrm{H}_{2} \mathrm{O}_{2}$ proceeds only in TFA. Contrary to oxidation in MeCN and DCM, cis-SOSO 6a was the major product in reaction in TFA and the selectivity for $6 \mathbf{a} / \mathbf{6 b}$ was higher at $0{ }^{\circ} \mathrm{C}$. Even after prolonged reaction time at room temperature no sulfone 7 is formed. Results show that TFA promotes oxidation through electrophilic process, which is evident by higher selectivity towards formation of sulfoxide products.

TFA therefore plays an important role in the activation of hydrogen peroxide for the oxidation of $\mathrm{ArSCF}_{3}$ and in the deactivation of further oxidation to sulfone. TFA could activate the electrophilic character of $\mathrm{H}_{2} \mathrm{O}_{2}$ for oxidation by hydrogen bonding, while the same interaction with the oxygen atom of the sulfoxide group would make the S-atom in $\mathrm{SOCF}_{3}$ more electrophilic and thus less reactive.

The same activation by TFA could also be effective in the reaction of trifluoromethylthiolation of aromatic molecules with the $\mathrm{ArNHSCF}_{3}$ reagent. Our goal was to combine both reactions the introduction of $\mathrm{SCF}_{3}$ group and its oxidation - in a one-pot process to incorporate $\mathrm{SOCF}_{3}$ group into the aromatic ring.

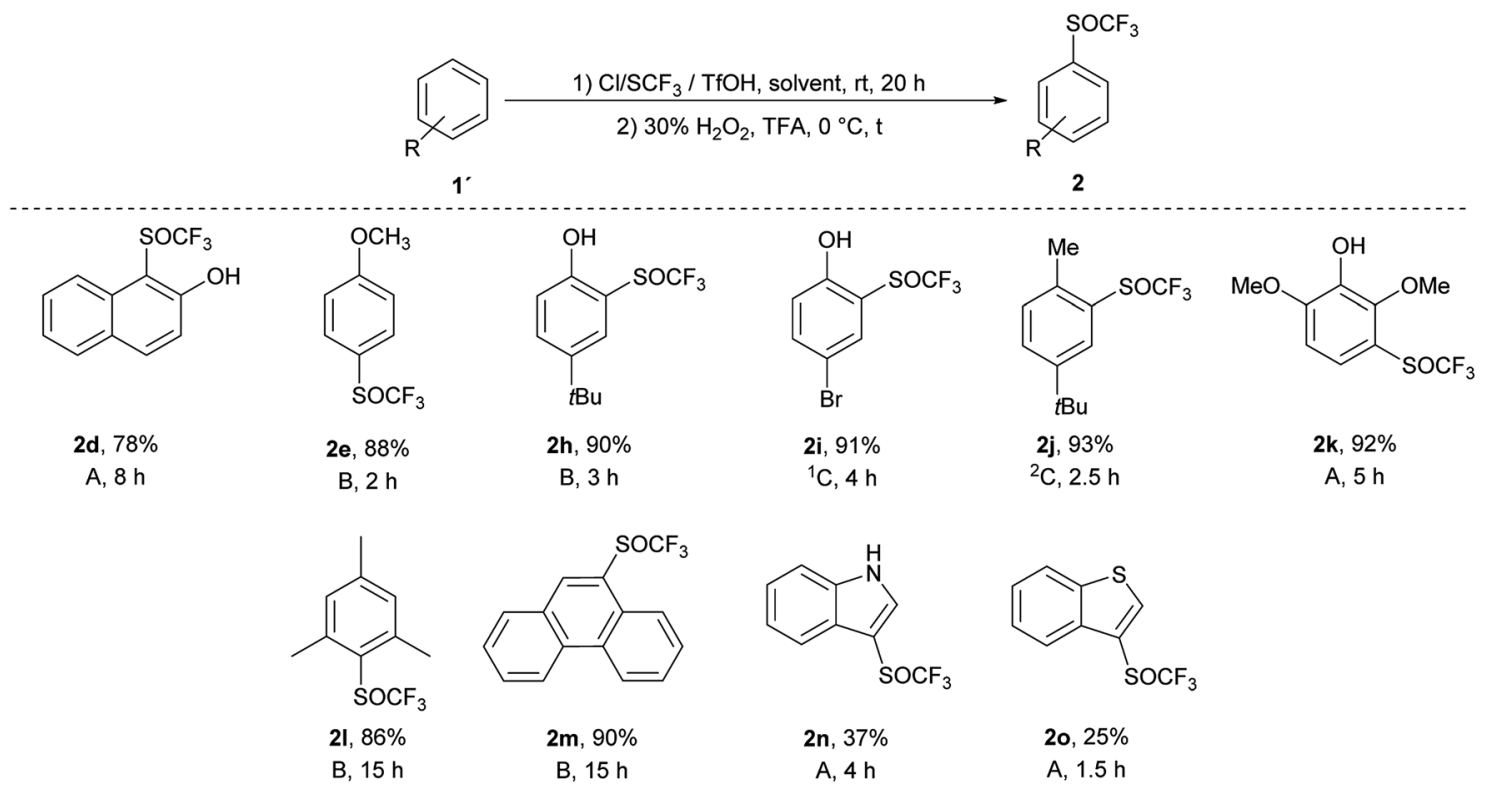

Scheme 5 Isolated yields of the trifluoromethyl sulfoxides 2. (1) (Method A: 1a : Cl/SCF $:$ TfOH = $1: 1.3: 1.3$, solvent: DCM; method B: 1a : Cl/ $\mathrm{SCF}_{3}: \mathrm{TfOH}=1: 1.3: 1.3$, stepwise addition of $\mathrm{Cl}_{\mathrm{SCF}}$, solvent: $\mathrm{DCM}$; method $\mathrm{C}: 1 \mathrm{a}: \mathrm{Cl} / \mathrm{SCF}$ : TfOH $=1: 2: 3$; stepwise addition of $\mathrm{Cl}_{\mathrm{SSCF}}$ and TfOH, solvent: ${ }^{1}$ hexane/ ${ }^{2}$ TFA ), rt, 20 h. (2) $\mathrm{H}_{2} \mathrm{O}_{2}(30 \%)$, TFA $(5 \mathrm{~mL}), t, 0{ }^{\circ} \mathrm{C}$. 
With these optimized reaction conditions in hand, we have investigated the possibility of selective and quantitative synthesis of trifluoromethyl sulfoxides $\mathbf{2}$ from different aromatic and heteroaromatic molecules $\mathbf{1}^{\prime}$ in one step. The reaction conditions for the preparation of trifluoromethyl sulfides 1 were taken from the reported reaction conditions. ${ }^{35} \mathrm{~A}$ solution of substrate $\mathbf{1}^{\prime}$, reagent $p$-ClPhNHSCF 3 , activator TfOH and solvent was stirred for $20 \mathrm{~h}$ at room temperature. The choice of the solvent depended on the reactivity of the arene (DCM, hexane or TFA). After completion of the reaction, TFA was added to the reaction mixture and cooled to $0{ }^{\circ} \mathrm{C} .1 .2$ equiv. of $30 \%$ aqueous hydrogen peroxide were added and the reaction time was followed by GC-MS.

Ten different products were prepared by one-pot process and the reactions were quantitative and selective as in both separate processes (Scheme 5). In general, this one-pot process generated the corresponding products in high yields (78-93\%), with the exception of heteroaromates $2 \mathrm{n}(37 \%)$ and 20 (25\%). Trifluoromethyl sulfoxides 2 were obtained in quantitative yields, without any trace of trifluoromethyl sulfone 3 . Compared to the classical two-step process, the one-pot method is faster, cheaper, easier to carry out and gives better yields (yields were 2 to $13 \%$ higher than in the classical two-step process).

\section{Conclusions}

In summary, we have developed the highly selective oxidation of aryl trifluoromethyl sulfides to the corresponding sulfoxides under metal-free conditions with $30 \% \mathrm{H}_{2} \mathrm{O}_{2}$. The oxidation was performed in the presence of $30 \%$ aqueous hydrogen peroxide as oxidant and TFA as solvent and activator. TFA proved to be effective in activating hydrogen peroxide and increasing selectivity by deactivating further oxidation to sulfone. Furthermore, we have investigated a new method for the direct introduction of $\mathrm{SOCF}_{3}$ functional group into various aromatic molecules. This method allows a simple and efficient synthesis of different trifluoromethyl sulfoxides from aromatic molecules by one-pot trifluoromethylthiolation with $p$-ClPhNHSCF${ }_{3}$ reagent followed by oxidation with $30 \% \mathrm{H}_{2} \mathrm{O}_{2}$. Mild reaction conditions and generally excellent yields were observed (78-93\%).

\section{Conflicts of interest}

There are no conflicts to declare.

\section{Acknowledgements}

Financial support of the Slovenian Research Agency (P1-0134, P1-0230) is greatly appreciated. The authors are grateful to the stuff of The Centre for Research Infrastructure at the Faculty of Chemistry and Chemical Technology (IC UL FCCT).

\section{Notes and references}

1 G. K. S. Prakash and Z. Zhang, in Modern Synthesis Processes and Reactivity of Fluorinated Compounds, ed. F. R. Leroux and
A. Tressaud, Elsevier, 2017, pp. 289-337, DOI: 10.1016/B9780-12-803740-9.00011-1.

2 X. Pannecoucke and T. Besset, Org. Biomol. Chem., 2019, 17, 1683-1693.

3 X. H. Xu, K. Matsuzaki and N. Shibata, Chem. Rev., 2015, 115, 731-764.

4 S. Barata-Vallejo, S. Bonesi and A. Postigo, Org. Biomol. Chem., 2016, 14, 7150-7182.

5 F. Toulgoat and T. Billard, in Modern Synthesis Processes and Reactivity of Fluorinated Compounds, ed. H. Groult, F. R. Leroux and A. Tressaud, Elsevier, 2017, pp. 141-179, DOI: 10.1016/B978-0-12-803740-9.00006-8.

6 H. Chachignon and D. Cahard, Chin. J. Chem., 2016, 34, 445454.

7 V. N. Boiko, Beilstein J. Org. Chem., 2010, 6, 880-921.

8 D. Bonnet-Delpon and J.-P. Bégué, Bioorganic and Medicinal Chemistry of Fluorine, John Wiley \& Sons, 2008.

9 C. Wakselman, M. Tordeux, C. Freslon and L. Saint-Jalmes, Synlett, 2001, 550-552.

10 H. Chachignon and D. Cahard, J. Fluorine Chem., 2017, 198, 82-88.

11 X. Chen, M. Tordeux, J.-R. Desmurs and C. Wakselman, J. Fluorine Chem., 2003, 123, 51-56.

12 T. Billard, A. Greiner and B. R. Langlois, Tetrahedron, 1999, 55, 7243-7250.

13 V. D. Romanenko, C. Thoumazet, V. Lavallo, F. S. Tham and G. Bertrand, Chem. Commun., 2003, 1680-1681.

14 M. Maeno, N. Shibata and D. Cahard, Org. Lett., 2015, 17, 1990-1993.

15 Z. Liu and R. C. Larock, J. Am. Chem. Soc., 2005, 127, 1311213113.

16 R. P. Singh, G. Cao, R. L. Kirchmeier and J. n. M. Shreeve, J. Org. Chem., 1999, 64, 2873-2876.

17 V. N. Movchun, A. A. Kolomeitsev and Y. L. Yagupolskii, J. Fluorine Chem., 1995, 70, 255-257.

18 R.-Y. Tang, P. Zhong and Q.-L. Lin, J. Fluorine Chem., 2007, 128, 636-640.

19 S. Gan, J. Yin, Y. Yao, Y. Liu, D. Chang, D. Zhu and L. Shi, Org. Biomol. Chem., 2017, 15, 2647-2654.

20 H. Marom, S. Antonov, Y. Popowski and M. Gozin, J. Org. Chem., 2011, 76, 5240-5246.

21 L. V. Sokolenko, I. I. Maletina, L. M. Yagupolskii and Y. L. Yagupolskii, Synlett, 2010, 2075-2078.

22 E. Baciocchi, M. F. Gerini and A. Lapi,J. Org. Chem., 2004, 69, 3586-3589.

23 A. Goti and F. Cardona, in Green Chemical Reactions. NATO Science for Peace and Security Series (Series C: Environmental Security), ed. P. Tundo and V. Esposito, Springer Netherlands, Dordrecht, 2008, pp. 191-212.

24 R. Noyori, M. Aoki and K. Sato, Chem. Commun., 2003, 19771986.

25 A. S. Rao, H. R. Mohan and J. Iskra, in Encyclopedia of Reagents for Organic Synthesis, ed. P. Fuchs, Wiley, 2013, DOI: 10.1002/047084289X.rh040.pub2.

26 K. Kaczorowska, Z. Kolarska, K. Mitka and P. Kowalski, Tetrahedron, 2005, 61, 8315-8327. 
27 S. Matavos-Aramyan, S. Soukhakian and M. H. Jazebizadeh, Phosphorus, Sulfur Silicon Relat. Elem., 2020, 195, 181-193.

28 F. Shi, M. K. Tse, H. M. Kaiser and M. Beller, Adv. Synth. Catal., 2007, 349, 2425-2430.

29 J. P. Begue, D. Bonnet-Delpon and B. Crousse, Synlett, 2004, 18-29.

30 V. L. Sokolenko, K. R. Orlova, A. A. Filatov, L. Y. Yagupolskii, E. Magnier, B. Pégot and P. Diter, Molecules, 2019, 24, 12491261.

31 X. Yang, T. Wu, R. J. Phipps and F. D. Toste, Chem. Rev., 2015, 115, 826-870.

32 Z. Huang and N. Shibata, in New Horizons of Process Chemistry: Scalable Reactions and Technologies, 2017, pp. 163-178, DOI: 10.1007/978-981-10-3421-3_12.

33 M. Jereb and K. Gosak, Org. Biomol. Chem., 2015, 13, 31033115.
34 Q. Glenadel, S. Alazet and T. Billard, J. Fluorine Chem., 2015, 179, 89-95.

35 M. Horvat, M. Jereb and J. Iskra, Eur. J. Org. Chem., 2018, 3837-3843.

36 K. S. Ravikumar, Y. M. Zhang, J. P. Begue and D. BonnetDelpon, Eur. J. Org. Chem., 1998, 2937-2940.

37 A. S. Rao, H. R. Mohan and A. Charette, in Encyclopedia of Reagents for Organic Synthesis, 2005, DOI: 10.1002/ 047084289X.rc140.pub2.

38 E. Eržen, J. Koller and B. Plesničar, J. Org. Chem., 2001, 66, 5155-5162.

39 W. Adam, W. Haas and G. Sieker, J. Am. Chem. Soc., 1984, 106, 5020-5022.

40 W. Adam and D. Golsch, J. Org. Chem., 1997, 62, 115-119. 